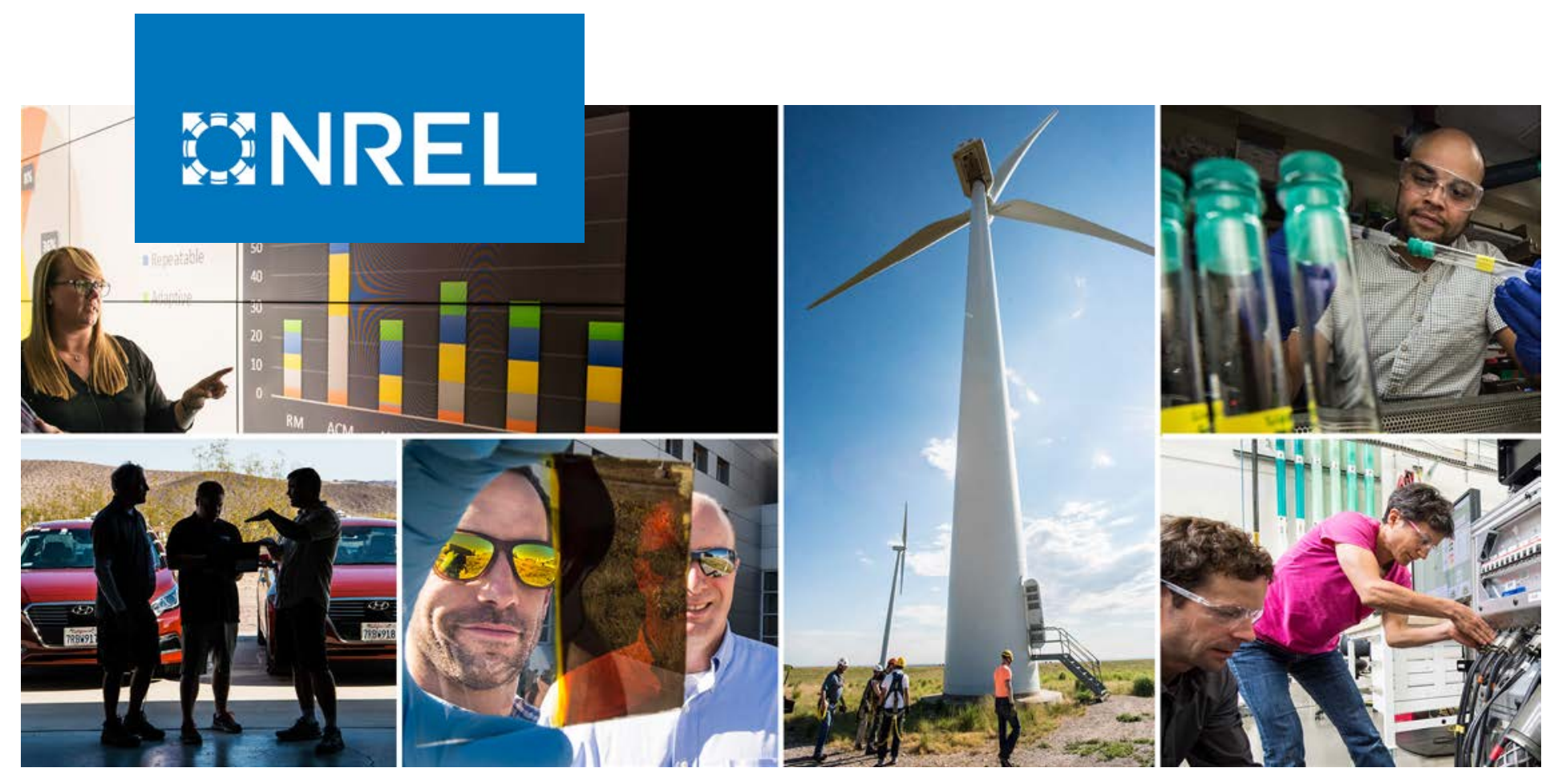

\title{
Equivalent Test Bed in PSCAD and PSLF for Studying Advanced Power Systems Controller Performance
}

\section{Preprint}

Reetam Sen Biswas, ${ }^{1,2}$ Jin Tan, ${ }^{2}$ Himanshu Jain, ${ }^{2}$

Vahan Gevorgian, ${ }^{2}$ and Yingchen Zhang ${ }^{2}$

${ }^{1}$ Arizona State University

${ }^{2}$ National Renewable Energy Laboratory

Presented at the 2019 IEEE Conference on Innovative Smart Grid Technologies (IEEE ISGT)

Washington, D.C.

February 17-20, 2019

NREL is a national laboratory of the U.S. Department of Energy

Office of Energy Efficiency \& Renewable Energy

Operated by the Alliance for Sustainable Energy, LLC

This report is available at no cost from the National Renewable Energy Laboratory (NREL) at www.nrel.gov/publications.
Conference Paper

NREL/CP-5D00-73106

July 2019 


\title{
WNREL
}

\section{Equivalent Test Bed in PSCAD and PSLF for Studying Advanced Power Systems Controller Performance}

\section{Preprint}

\author{
Reetam Sen Biswas, ${ }^{1,2}$ Jin Tan, ${ }^{2}$ Himanshu Jain, ${ }^{2}$ \\ Vahan Gevorgian, ${ }^{2}$ and Yingchen Zhang ${ }^{2}$ \\ ${ }^{1}$ Arizona State University \\ ${ }^{2}$ National Renewable Energy Laboratory
}

\section{Suggested Citation}

Sen Biswas, Reetam, Jin Tan, Himanshu Jain, Vahan Gevorgian, and Yingchen Zhang. 2019. Equivalent Test Bed in PSCAD and PSLF for Studying Advanced Power Systems Controller Performance: Preprint. Golden, CO: National Renewable Energy Laboratory. NREL/CP-5D00-73106. https://www.nrel.gov/docs/fy19osti/73106.pdf.

(C) 2019 IEEE. Personal use of this material is permitted. Permission from IEEE must be obtained for all other uses, in any current or future media, including reprinting/republishing this material for advertising or promotional purposes, creating new collective works, for resale or redistribution to servers or lists, or reuse of any copyrighted component of this work in other works.

NREL is a national laboratory of the U.S. Department of Energy Office of Energy Efficiency \& Renewable Energy Operated by the Alliance for Sustainable Energy, LLC

This report is available at no cost from the National Renewable Energy Laboratory (NREL) at www.nrel.gov/publications.

Contract No. DE-AC36-08GO28308
Conference Paper NREL/CP-5D00-73106 July 2019

National Renewable Energy Laboratory 15013 Denver West Parkway Golden, CO 80401 303-275-3000 • www.nrel.gov 


\section{NOTICE}

This work was authored by the National Renewable Energy Laboratory, operated by Alliance for Sustainable Energy, LLC, for the U.S. Department of Energy (DOE) under Contract No. DE-AC36-08GO28308. Funding provided by U.S. Department of Energy Office of Energy Efficiency and Renewable Energy Solar Energy Technologies Office. The views expressed herein do not necessarily represent the views of the DOE or the U.S. Government. The U.S. Government retains and the publisher, by accepting the article for publication, acknowledges that the U.S. Government retains a nonexclusive, paid-up, irrevocable, worldwide license to publish or reproduce the published form of this work, or allow others to do so, for U.S. Government purposes.

This report is available at no cost from the National Renewable Energy Laboratory (NREL) at www.nrel.gov/publications.

U.S. Department of Energy (DOE) reports produced after 1991 and a growing number of pre-1991 documents are available free via www.OSTI.gov.

Cover Photos by Dennis Schroeder: (clockwise, left to right) NREL 51934, NREL 45897, NREL 42160, NREL 45891, NREL 48097, NREL 46526.

NREL prints on paper that contains recycled content. 


\title{
Equivalent Test Bed in PSCAD and PSLF for Studying Advanced Power Systems Controller Performance
}

\author{
Reetam Sen Biswas ${ }^{1,2}$, Jin Tan ${ }^{1}$, Himanshu Jain ${ }^{1}$, Vahan Gevorgian ${ }^{1}$,Yingchen Zhang ${ }^{1}$ \\ 1. National Renewable Energy Laboratory, Golden, CO 80401 \\ 2. Arizona State University, Tempe, AZ 85287
}

\begin{abstract}
With increasing popularity of sustainable energy resources, research on power electronic-based renewable generation modeling is gaining impetus to enhance reliability of electric grids with high penetrations of renewable energy. A set of generic and public models for renewable energy are available in commercial positive sequence power system simulation software. However, advanced controller models applicable for renewable resources are typically not included in these tools. To ensure the integrity of the newly developed controller models for renewables in positive sequence simulators for large power systems, it is necessary to validate the dynamic performance of the proposed model with detailed electromagnetic models. This paper creates an equivalent test bed in PSCAD and PSLF for validating the performance of advanced controllers associated with renewable energy sources. To demonstrate the usefulness of the test-bed, a user-defined synthetic inertia (SI) controller model was developed in PSLF and validated through the proposed test bed.
\end{abstract}

Index Terms-Renewable energy modeling, PSLF, Synthetic inertia, PSCAD

\section{INTRODUCTION}

Power system transient stability analysis, both in terms of short-term rotor angle stability and voltage stability, is conducted for reliable operation of power systems [1]. This becomes even more important with burgeoning renewable generation penetration in the grid [2]. Per the state's renewable portfolio standards [3], California has set an ambitious goal of realizing $50 \%$ renewable energy procurement by 2030 . As such, the electric utilities are trying to enhance their renewable energy penetration level without violating the Western Electricity Coordinating Council (WECC) transmission system planning criteria [4]. Hence, identifying the maximum threshold for renewable energy penetration without incurring stability limit violations is an important domain of research. With increasing penetration levels of inverter-based generation, the inherent inertia of the grid to respond to transient events such as loss of a generator and load change diminishes [5]. As a result, there is growing interest in deploying advanced control strategies in renewable energy resource inverters so that these resources can provide reliability support to the grid, a function that has hitherto been the domain of synchronous generators. Synthetic inertia (SI) controllers are an example of such advanced control techniques being added to the renewable energy resource inverters [6].
As the new controllers are deployed, a key challenge for power system planners is to understand the performance of the controllers and their impact on the dynamics of the bulk power system. Electromagnetic transient (EMT) simulation programs enable the most accurate evaluation of the performance of the inverters and their control strategies. However, excessive simulation time for EMT simulations makes it hard to apply these models to large-scale planning studies where several scenarios may need to be run on power system models with several tens of thousands of buses. To overcome this limitation, simplified models that are well suited for electromechanical transient simulations are developed and used for large-scale planning studies. The simplified models must closely replicate the behavior of the inverters and their controllers at the time scales of interest in the electromechanical simulations. In light of this discussion, this paper presents the work that we have done to develop an equivalent test bed in PSCAD and PSLF that can be used to (i) evaluate the performance of the inverter models and their advanced controllers, (ii) develop and validate simplified electromechanical transient simulation inverter models for large-scale planning studies in positive sequence simulators.

The general strategy of developing a new controller model in a positive sequence software is as follows: (i) Perform laboratory experiments and field testing to find out the model parameters of the controller accurately, (ii) implement the detailed model of the controller in an electromagnetic software such as PSCAD/EMTDC and finally, (iii) implement the slower electromechanical dynamics of the controller in a positivesequence simulator. Once, the slower dynamics of the controller are modeled in PSLF, it is necessary to validate the performance of the controller (in PSLF and PSCAD) with respect to a reference system. The key challenges in finding the reference test-bed where the controller model can be validated are as follows:

1) It is very difficult to find a reference system with identical machine models in PSLF and PSCAD because each software may not have all the models in their respective model libraries. The generator, governor and excitation system modeling might not be the same in electromagnetic and electro-mechanical environments. As a result, it is essential to select the closest models in the respective software and fine-tune the machine parameters to obtain similar dynamic response. 
2) Secondly, the initialization technique of the system dynamic states with the base-case power flow is different between PSCAD and PSLF. Therefore, bringing the models in the two software to the same steady-state before initiating a disturbance can be a challenging task.

In this paper, the above challenges are addressed using a methodical approach. The nuances of the initialization methodology in PSLF and PSCAD are briefly discussed, which might be useful to future researchers working with software such as PSLF and PSCAD. Unlike the conventional generator models, power-electronic based models have faster switching characteristics, which can only be appropriately modeled in electromagnetic simulation platform. However, such modeling is not feasible using electromechanical simulation because it only characterizes the slower dynamics of the system. In this respect, this paper differs from prior research [7]-[11] in the domain of model validation in the following way: it produces an equivalent platform to develop and validate any user-defined model in electromechanical transient stability software such as PSLF from the detailed electromagnetic modeling in PSCAD. In addition, the PSCAD version of the proposed test bed would be useful to study unbalanced fault scenarios that cannot be studied in positive sequence simulators.

The rest of the paper is structured as follows. Section II describes the methodical approach that was used to realize the desired objective. It enumerates the steps of how the compatibility of the test bed was maintained in both PSCAD and PSLF. Section III demonstrates the utility of the equivalent test bed to validate a user-defined synthetic inertia controller in PSLF from its detailed implementation in PSCAD. Finally, Section IV summarizes the major contributions of this research.

\section{Proposed METHODOLOGY}

The IEEE 9-bus system was used to create two equivalent standard test cases in PSCAD and PSLF. The power flow data for the system is available in [12]. Following steps were followed to create the equivalent test bed:

Step 1: Validate the power flow in PSLF and PSCAD.

Step 2: Select the equivalent machine models.

Step 3: Obtain close pre-disturbance steady state in the two software.

Step 4: Fine-tune the machine parameters.

Step 5: Integrate a renewable energy resource in the network.

These steps, and the results obtained at each step are described in detail next.

Step 1: The power flow results of the standard IEEE 9-bus system are validated in Table I. The errors in voltage magnitude and phase angle in PSLF and PSCAD are between \pm 0.001 p.u. and $\pm 0.04^{\circ}$, respectively.

Step 2: After the successful validation of the power flow results, the closest dynamic models of the synchronous generators were selected in PSCAD and PSLF. With reference to the standard IEEE 9-bus system, the different machine models that were used in the two software platforms are summarized in Table II. Among the three generators, two were modeled as steam power plants and third was modeled as a hydropower plant.

Table I: Power flow results in PSCAD and PSLF

\begin{tabular}{|c|c|c|c|c|c|c|}
\hline & \multicolumn{2}{|c|}{ PSLF } & \multicolumn{2}{c|}{ PSCAD } & \multicolumn{2}{c|}{ Error } \\
\hline & $\begin{array}{c}\text { Volt. } \\
\text { Mag. } \\
\text { (p.u.) }\end{array}$ & $\begin{array}{c}\text { Volt. } \\
\text { Ang. } \\
\text { (deg.) }\end{array}$ & $\begin{array}{c}\text { Volt. } \\
\text { Mag. } \\
\text { (p.u.) }\end{array}$ & $\begin{array}{c}\text { Volt. } \\
\text { Ang. } \\
\text { (deg.) }\end{array}$ & $\begin{array}{c}\text { Volt. } \\
\text { Mag. } \\
\text { (p.u.) }\end{array}$ & $\begin{array}{c}\text { Volt. } \\
\text { Ang. } \\
\text { (deg.) }\end{array}$ \\
\hline Bus 1 & 1.04 & 0 & 1.039 & 0.021 & 0.001 & 0.021 \\
\hline Bus 2 & 1.025 & 9.35 & 1.025 & 9.33 & 0 & 0.020 \\
\hline Bus 3 & 1.025 & 5.14 & 1.024 & 5.12 & 0.001 & 0.020 \\
\hline Bus 4 & 1.025 & -2.22 & 1.025 & -2.19 & 0 & -0.030 \\
\hline Bus 5 & 0.999 & -3.68 & 0.9996 & -3.64 & -0.0006 & -0.04 \\
\hline Bus 6 & 1.012 & -3.57 & 1.012 & -3.53 & 0 & -0.04 \\
\hline Bus 7 & 1.027 & 3.80 & 1.026 & 3.77 & 0.001 & 0.030 \\
\hline Bus 8 & 1.017 & 1.34 & 1.017 & 1.32 & 0 & 0.02 \\
\hline Bus 9 & 1.033 & 2.44 & 1.032 & 2.42 & 0.001 & 0.02 \\
\hline
\end{tabular}

Table II: Equivalent machine models in PSCAD and PSLF

\begin{tabular}{|c|c|c|c|}
\hline Type & Equipment & PSCAD & PSLF \\
\hline \multirow{2}{*}{$\begin{array}{c}\text { Hydro- } \\
\text { power } \\
\text { plant at } \\
\text { bus 2 }\end{array}$} & Generator & Sync1 & Genrou \\
\cline { 2 - 4 } & Exciter & AC1A & Exac1 \\
\cline { 2 - 4 } & Turbine/Governor & $\begin{array}{c}\text { Hydro Tur1 } \\
\text { /Hydro Gov 1 }\end{array}$ & Hygov4 \\
\hline $\begin{array}{c}\text { Steam } \\
\text { power } \\
\text { plant at } \\
\text { bus 1 } \\
\text { and 3 }\end{array}$ & Generator & Sync1 & Genrou \\
\cline { 2 - 4 } & Exciter & AC1A & Exac1 \\
\cline { 2 - 4 } & & $\begin{array}{c}\text { Steam Tur1/ } \\
\text { Steam Gov4 }\end{array}$ & Ieeeg1 \\
\hline
\end{tabular}

Step 3: Initialization methodology can vary between software. For example, in PSLF, when the "Ieeeg1" governor model was initialized, the initial valve position of the turbine gate was automatically selected based on the initial power flow and the contribution coefficients of the low-pressure and high-pressure turbines; however, in PSCAD, the initial valve position needed to be set manually before the dynamic simulations could be started. In this regard, the nuances of the initialization mechanism of the electromagnetic and electromechanical software were addressed before running the time-domain simulations.

Step 4: As the next step, many trials of time-domain simulation were run in PSCAD and PSLF to fine-tune the machine parameters. The successful tuning of the machine parameters is clear from the time-domain response of the three generators for a three-cycle bolted fault applied at bus 8. Fig. 1 compares the voltage profile of the generators in PSCAD and PSLF, which match closely between the two software. 

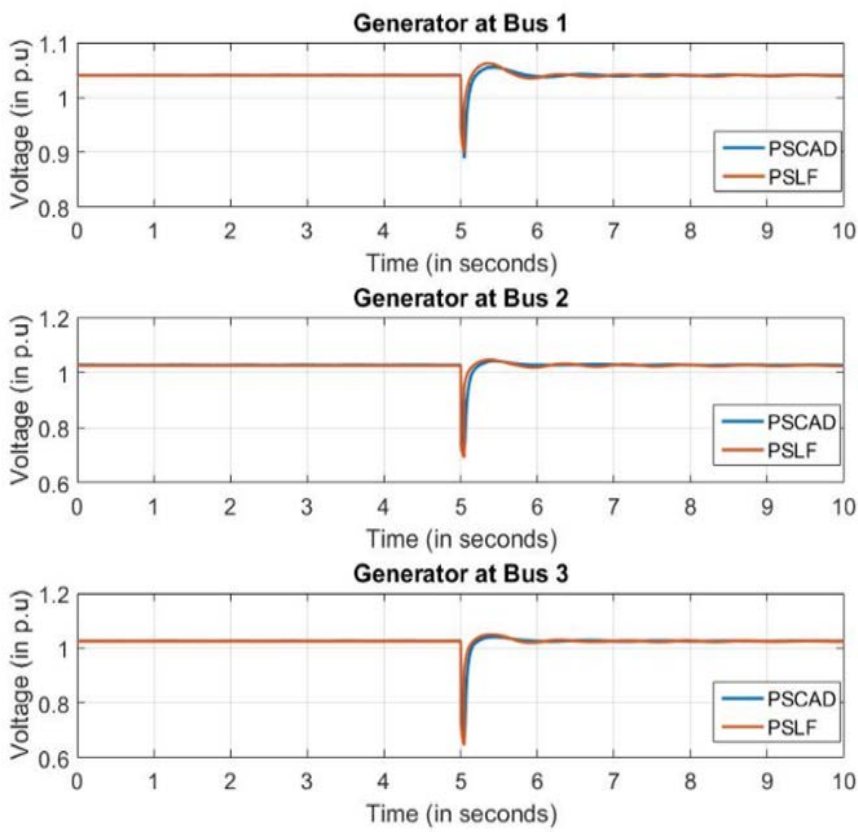

Fig. 1: Comparison of terminal voltage of different generators in the IEEE 9-bus system

Step 5: A renewable energy resource was added in the system at bus 5. In PSLF the generic generator/converter model "regc a" is used to represent renewable generation. The "reec_a" electrical control model is used for wind power generation. Similarly, the electrical control model used for representing "solar PV" and "battery energy storage" are "reec_b" and "reec_c". A simplified model based on constant current injection was used in PSCAD to correspond to the slower dynamics of the system in PSLF. To compare the frequency response of the system, $30 \mathrm{MW}$ of load is suddenly increased at bus 6 . Fig. 2 shows that the profile of frequency measured at bus 3 matches very closely in PSCAD and PSLF. Fig. 3 compares the active power response of the generator at bus 3 .

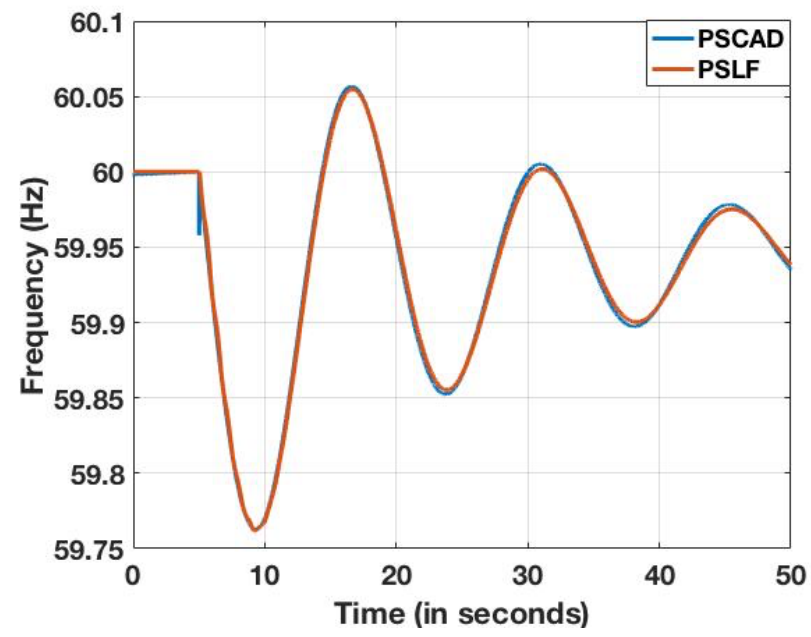

Fig. 2: Frequency variation at bus 3, observed in PSCAD and PSLF

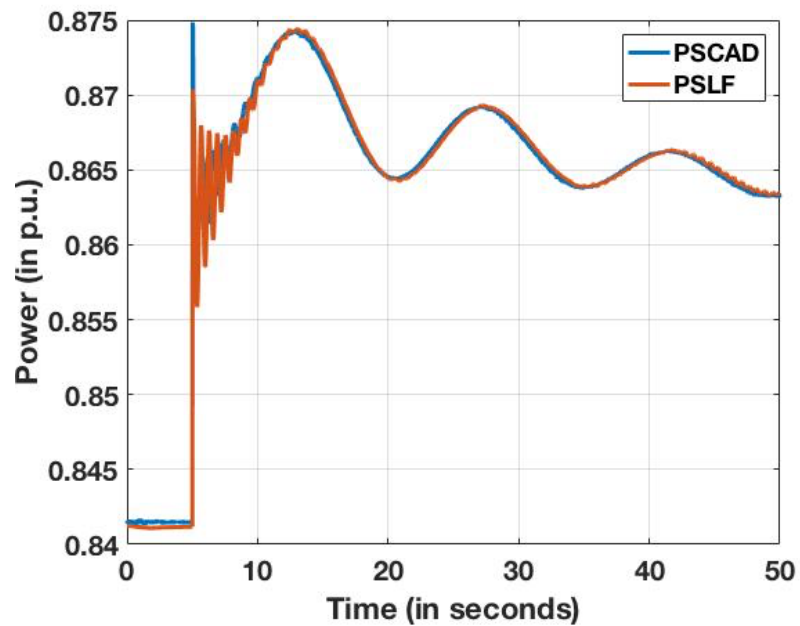

Fig 3: The active power response of the generator at bus 3 .

For quantitative comparison of the active power response of the generators in PSLF and in PSCAD two metrics were used: the root means square error (RMSE) and cross correlation coefficients (CCF) between the signals in PSCAD and PSLF. The RMSE shows the closeness of the results between PSLF and PSCAD, while the property of cross-correlation detects the degree of similarity of one-signal with respect to the other signal. Table III lists the RMSE in frequency and the active power at the generator buses of the network. Table IV compares the correlation coefficient between the frequency response and active power response in PSCAD and PSLF. Since, the correlation coefficients are close to 1 as observed from the table, the frequency and the active power response of the system in the two software is equivalent.

Table III: Errors between the frequency response and the active power response in PSCAD and PSLF

\begin{tabular}{|c|c|c|}
\hline & RMSE in Freq. (Hz) & RMSE in Power (MW) \\
\hline Generator 1 & 0.0031 & 0.0024 \\
\hline Generator 2 & 0.0031 & 0.0024 \\
\hline Generator 3 & 0.0031 & 0.0008 \\
\hline
\end{tabular}

Table IV: Correlation between the frequency response and the active power response in PSCAD and PSLF

\begin{tabular}{|c|c|c|}
\hline & CCF in Freq. (Hz) & CCF in Power (MW) \\
\hline Generator 1 & 0.999 & 0.991 \\
\hline Generator 2 & 0.999 & 0.983 \\
\hline Generator 3 & 0.999 & 0.995 \\
\hline
\end{tabular}

\section{Application Of The Test Bed}

The testbed created was used to validate the modeling of the SI controller in PSLF from the detailed device-level modeling in PSCAD. For this purpose, renewable energy resource (wind, solar PV, or BESS) associated with SI controllers is integrated into the system at bus 5, as shown in Fig. 4. A rate of change of frequency based synthetic inertia controller was designed, 
associated with the renewable energy sources. The local frequency of the system measured from bus 5 is used as the input to the SI controller. For synchronous machines, the inertial response is the spontaneous release of the stored kinetic energy of the rotating rotor. Because of the imbalance of active power generated by the active power loading of a generator, the rate of change of frequency (ROCOF) is obtained from the swing equation, shown in (1):

$\frac{2 H}{\omega_{s}}\left(\frac{d \omega}{d t}\right)=P_{\text {gen }}-P_{\text {load }}$

where $P_{\text {gen }}$ denotes the mechanical power produced by the generator in per unit, $P_{\text {load }}$ denotes the electrical load on the machine in per unit, $H$ is the inertia constant (in $s$ ), and $\omega$ is the system angular frequency in $\mathrm{rad} / \mathrm{s}$ and $\omega_{s}$ is the synchronous speed in $\mathrm{rad} / \mathrm{s}$.

Thus, to model the SI associated with RES, equation (1) is replicated by developing an equivalent transfer function. As shown in Fig. 4, the $s T_{2}$ is the main block that produces the ROCOF. $\frac{G_{1}}{1+s T_{1}}$ is the low-pass filter block. For hardware implementation, accurate measurement of $\frac{d f}{d t}$ is associated with a noise amplification process. To nullify the low frequency noise, the low-pass filter block is used. The ROCOF $\frac{d f}{d t}$ is multiplied by $H$ to obtain the equivalent change in power output in per unit. Selection of an equivalent inertia constant $H$ for renewables should be done in perspective of the desired amount of primary frequency support to be provided by the controller. Finally, the $\Delta P$ in per unit is multiplied by the base MVA rating of the RES to obtain the required change in active power in $\mathrm{MW}$. The $\triangle P$ in $\mathrm{MW}$ is the desired change in power output of the RES in response to $\Delta f$. Hence, the $\Delta P$ goes into the corresponding electrical control model-e.g., "reec_a", "reec_b", and "reec_c"- to change the power output of the generator/convertor model "regc_a" by an appropriate amount.

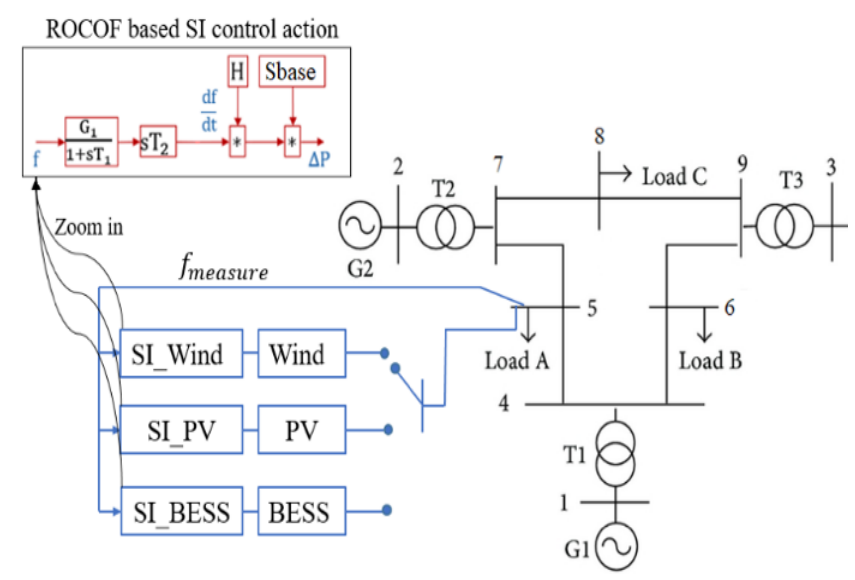

Fig. 4: Simple modeling of SI controller
As the first step to validate the performance of the SI controller action in PSLF, open-loop test was performed. It is called this because the test is done in isolation from the network. A step change in frequency (from 1 p.u. to 0 p.u.) is applied at the input of the SI controller at $5 \mathrm{~s}$, which is depicted in Fig. 5. The response of the SI controller in PSLF and PSCAD is observed to be the same in the two software (see Fig. 6). The moment grid frequency falls from 1 p.u. to 0 p.u., the SI control action increases the active power output of the renewable generator as a frequency support mechanism. As the second step of model validation, the SI control action is validated using the proposed test bed. Fig. 7 and 8 depict the frequency response of the network and the active power response of a renewable machine when it is integrated into the grid with its corresponding SI controller. The renewable machine of 6-MVA rating is currently operating at a power output of $5 \mathrm{MW}$. When $30 \mathrm{MW}$ of load at bus 6 is increased at 1 second, the grid frequency dips as expected (see Fig. 7). In response to the momentary frequency dip, the renewable machine increases its active power output by virtue of its controller action (refer Fig. 8). Since, the renewable machine has a headroom of $1 \mathrm{MW}$, the active power output of the generator reaches a maximum of approximately $5.8 \mathrm{MW}$. The active power response of the renewable source is similar in PSLF and PSCAD, which validates the frequency control action of the SI model built in PSLF.

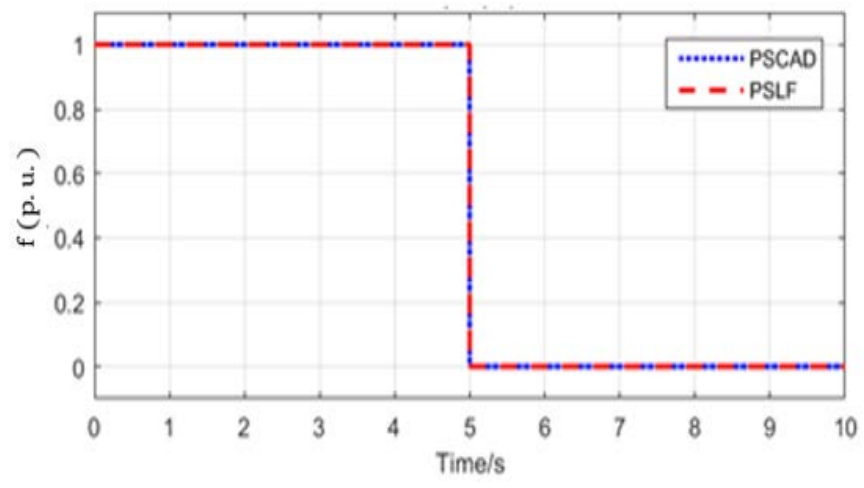

Fig. 5: Step change in input frequency signal, at input of SI controller.

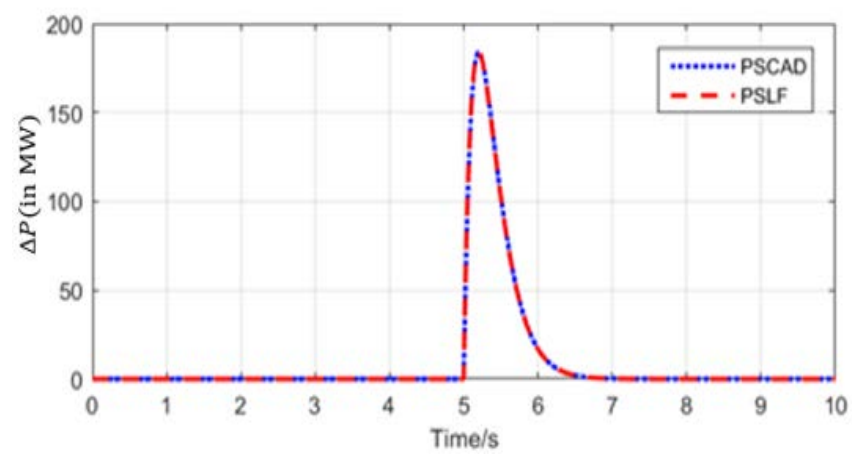

Fig. 6: Response of the SI controller in PSCAD and PSLF 


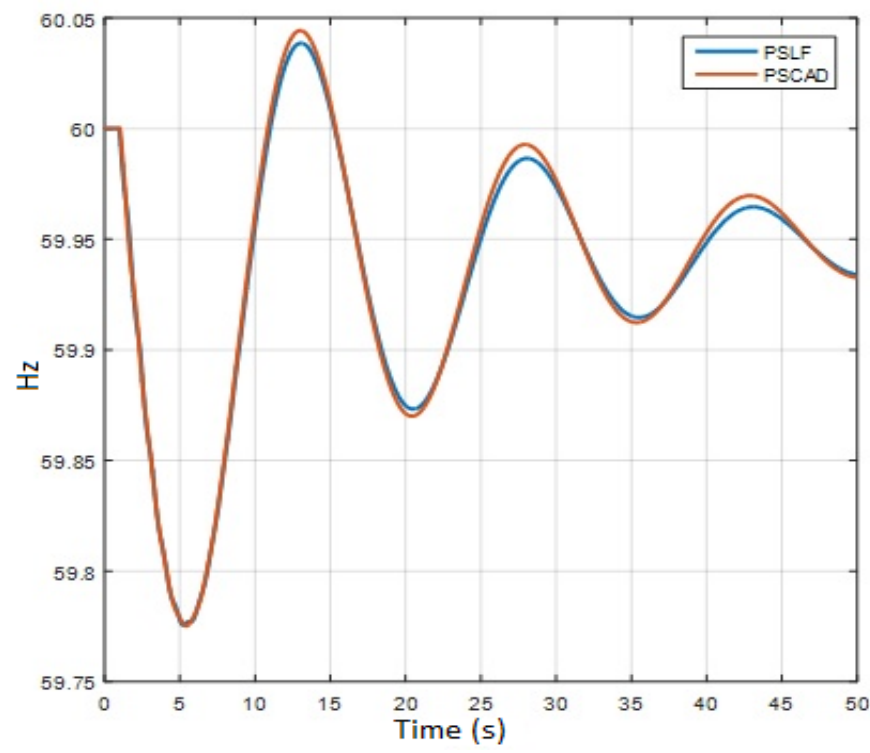

Fig. 7: Frequency response of the 9-bus system

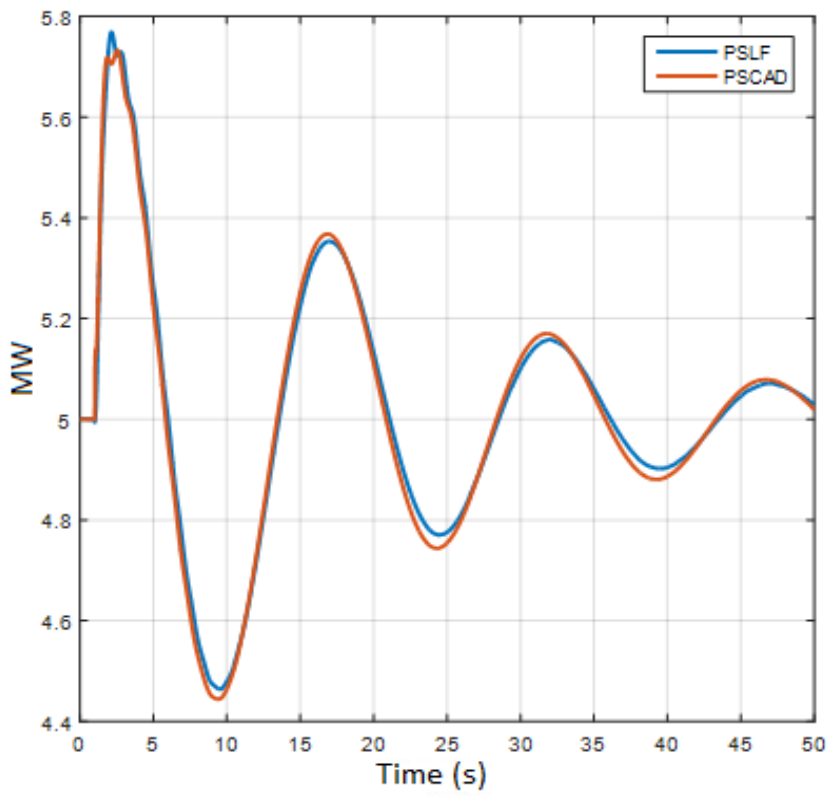

Fig. 8: Active power response of the BESS.

\section{CONCLUSION}

The work proposed in this paper helped to create identical test beds in electromechanical and electromagnetic transient stability software. The uniqueness of the proposed test bed is that it provides the basis for testing the frequency response of SI controllers. In this paper, the proposed test bed helped to validate the modeling of the SI controller in PSLF from the detailed device-level modeling in PSCAD. In this perspective, the proposed test bed could be useful to validate the performance of advanced controllers of electronic-based renewable generators for a variety of applications.
The validated SI model is currently being used to evaluate the impact of provision of SI from solar PV and battery storage on a $20,000+$ bus Western Interconnection model under very high renewable penetration levels.

The key contributions of this research can be summarized as follows:

- Appropriate parameters of the equivalent machine models for the synchronous generators of the standard 9-bus system are selected in PSCAD and PSLF to attain the same dynamic response.

- Even after integrating a renewable energy resource (wind, solar PV, or BESS), the same dynamic response and frequency response of the system is maintained in PSCAD and PSLF.

- In Section IV, it was demonstrated how the proposed test bed can be beneficial to investigate the frequency response of the SI controllers.

- NREL will make the power flow file and dynamic file of the developed equivalent IEEE 9-bus model in PSCAD and PSLF publicly available, so that researchers can use them to validate the dynamic performance of inverterbased generation model and advanced controllers.

\section{REFERENCES}

[1] S. S. Refaat, H. Abu-Rub, A. P. Sanfilippo and A. Mohamed, "Impact of grid-tied large-scale photovoltaic system on dynamic voltage stability of electric power grids," IET Renew. Power Gener., vol. 12, no. 2, pp. 157164, Feb. 2018.

[2] Renewable energy policy network for the $21^{\text {st }}$ century, "Renewables 2017 global status report.” Available online: http://www.ren21.net/wpcontent/uploads/2017/06/178399_GSR_2017_Full_Report_0621_Opt.pdf

[3] California Energy Commission, "Developing guidelines for the 50 percent renewables portfolio standard." Available online: https://efiling.energy.ca.gov/getdocument.aspx?tn=217317.

[4] Western Electricity Coordinating Council, "WECC Criteria, TPL-001WECC-CRT-3.1." Available online: https://www.wecc.biz/Reliability/TPL-001-WECC-CRT-3.1.pdf.

[5] V. Gevorgian, Y. Zhang and E. Ela, "Investigating the impacts of wind generation participation in interconnection frequency response," IEEE Trans. Sustainable Energy, vol. 6, no. 3, pp. 1004-1012, Jul. 2015.

[6] H. Dharmawardena, K. Uhlen and S. S. Gjerde, "Modelling wind farm with synthetic inertia for power system dynamic studies," in Proc. 2016 IEEE Int. Energy Conf. (ENERGYCON), Leuven, pp. 1-6, Apr. 2016.

[7] K. K. Kaberere, K. A. Folly and A. I. Petroianu, "Assessment of commercially available software tools for transient stability: experience gained in an academic environment," in Proc. 2004 IEEE 7th Africon Conf., Africa (IEEE Cat. No.04CH37590), pp. 711-716, Sep. 2004.

[8] T. Overbye and M. Venkatasubramanian, "Validation and accreditation of transient stability results," PSERC publication, Sep. 2011.

[9] H. Teng, C. Liu, M. Han, S. Ma and X. Guo, "IEEE 9 buses system simulation and modeling in PSCAD," in Proc. 2010 Asia-Pacific Power Energy Eng. Conf., Chengdu, pp. 1-4, Mar. 2010.

[10] M. Z. Kamh and R. Iravani, "Three-phase steady-state model of type-3 wind generation unit-Part II: model validation and applications," IEEE Trans. Sustainable Energy, vol. 3, no. 1, pp. 41-48, Jan. 2012.

[11] S. Bu, W. Du and H. Wang, "Model validation of DFIGs for power system oscillation stability analysis," IET Renew. Power Gener., vol. 11, no. 6, pp. 858-866, Oct. 2017.

[12] Illinois Center for a Smarter Electric Grid, "WSCC 9-bus system." Online Available: http://icseg.iti.illinois.edu/wscc-9-bus-system/ 